\title{
$\begin{array}{ll}\text { Research Square } & \text { Preprints are preliminary reports that have not undergone peer review. } \\ \text { They should not be considered conclusive, used to inform clinical practice, } \\ \text { or referenced by the media as validated information. }\end{array}$
}

\section{Predictors of exacerbations of pulmonary MAC disease}

\author{
Norio Kodaka \\ Toho University Ohashi Medical Center \\ Chihiro Nakano \\ Toho University Ohashi Medical Center \\ Takeshi Oshio \\ Toho University Ohashi Medical Center \\ Kayo Watanabe \\ Toho University Ohashi Medical Center \\ Kumiko Niitsuma \\ Toho University Ohashi Medical Center \\ Chisato Imaizumi \\ Toho University Ohashi Medical Center \\ Hiroto Matsuse ( $\square$ hiroto.matsuse@med.toho-u.ac.jp) \\ Toho University Ohashi Medical Center https://orcid.org/0000-0003-0242-5005
}

\section{Research article}

Keywords: Mycobacterium avium complex, nontuberculous mycobacterium, sex, smoking status

Posted Date: September 26th, 2019

DOI: https://doi.org/10.21203/rs.2.12024/v2

License: @ (i) This work is licensed under a Creative Commons Attribution 4.0 International License. Read Full License 


\section{Abstract}

Background and Objectives The number of patients with pulmonary Mycobacterium avium complex (MAC) disease is increasing worldwide, especially among middle-aged women and never-smokers. Although sex and smoking status have attracted attention as predictors of the development and exacerbation of pulmonary MAC disease, the exact associations remain unknown.The aim of the present study was to clarify the associations of sex and smoking status with the clinical characteristics of pulmonary MAC disease and to identify the predictors of exacerbations of pulmonary MAC disease. Methods From April 2011 to May 2016, 128 MAC patients at our institute were newly diagnosed with pulmonary MAC disease according to the 2007 American Thoracic Society/Infectious Disease Society guideline. Their medical records were retrospectively examined for their clinical findings. The radiological findings at the time of the diagnosis and 1 year later were evaluated. Clinical characteristics were compared by smoking status and sex. To identify the natural predictors of exacerbation, multivariable analysis was performed with the data of 80 treatment-naïve patients. Results Female, neversmoker, and nodular/bronchiectatic (NB) type were common in patients with pulmonary MAC disease. Univariate analysis of data from treatment-naïve subjects showed that female, never-smoker, fewer lung diseases other than MAC, extensive radiological findings, and $\geq 3$ lobes involved were significantly associated with exacerbations. On multivariate analysis, fewer lung diseases other than MAC, extensive radiological findings, and $\geq 3$ lobes involved were significantly associated with exacerbations, but female and never-smoker were not. Conclusions In this study, the presence of extensive radiological findings, especially abnormal shadows in $\geq 3$ lobes and absence of lung diseases other than MAC, rather than sex and smoking status, was a predictor of exacerbations of treatment-naïve pulmonary MAC disease.

\section{Introduction}

Epidemiologic data suggest that the incidence and prevalence of nontuberculous mycobacterium (NTM) infections are increasing in many countries. ${ }^{1-6}$ Mycobacterium avium complex (MAC), including M. avium and M. intracellulare, is the most common aetiology in NTM. ${ }^{7,8}$ Although the progressive improvements in diagnostic technology such as chest computed

tomography (CT) and genetic sequencing suggest that host and microorganism factors, ${ }^{9-12}$ as well as environmental factors, ${ }^{12}$ might be involved, the exact reason for the increasing prevalence of MAC remains unknown.

The clinical outcomes of pulmonary MAC disease vary widely. Some patients respond well to standard treatment including clarithromycin, ethambutol, and rifampicin, whereas others show resistance to standard treatment with poor outcomes, and some other patients remain stable without any treatment. ${ }^{7,13}$ Thus, it is critical to determine the predictors for the prognosis of patients with pulmonary MAC disease.

It has long been considered that the causative species are critical predictors, but the difference in the prognosis between $M$. avium and $M$. intracellulare infections still remains uncertain. ${ }^{14,15}$

Sex and smoking status have also attracted attention as predictors of exacerbations of pulmonary MAC disease. The prevalence of pulmonary MAC disease is increasing particularly in never-smokers and middle-aged women. ${ }^{7,8,16}$ The effects of female hormones and adiponectin have been implicated, ${ }^{17}$ though the underlying mechanisms are yet to be determined.

The aim of the present study was to clarify the associations of sex and smoking status with the clinical characteristics of pulmonary MAC disease and to determine the significant predictors of exacerbations of pulmonary MAC disease.

\section{Methods}

\section{Study population}

From April 2011 to May 2016 at our institute, of the patients with suspected NTM, 315 NTM subjects were newly identified by cultures. Of them, 143 were diagnosed with NTM disease according to the 2007 American Thoracic Society/Infectious 
Disease Society guideline. $^{7}$ Those with a past history of NTM disease and NTM other than MAC were excluded from the present study. Finally, 128 subjects were enrolled in the present study (Figure 1). Clinical findings of the subjects including age, sex, past history of tuberculosis, laboratory data, and radiological findings were retrospectively examined from their medical records. To clarify the associations of sex and smoking status with the clinical characteristics of pulmonary MAC disease, the subjects were divided by sex and smoking status. To identify the significant predictors and to exclude treatment bias, analysis of only treatment-naïve subjects (patients who did not receive medications for MAC during the observation period) was also performed.

\section{Microbiological examination}

Acid-fast bacilli (AFB) were cultured in a Mycobacteria Growth Indicator Tube (MGIT) from extracted sputum or bronchial washings obtained by bronchoscopy. The sputum samples were obtained on two or more occasions after the initial presentation. The diagnosis of MAC was confirmed when cultures were positive for AFB, and the cultured AFB was subsequently confirmed as MAC by PCR. The diagnosis of pulmonary MAC disease was established when MAC was identified in sputum at least twice or in bronchial washings.

\section{Radiological examination}

According to a previous report, ${ }^{7}$ chest radiological findings were classified as fibrocavitary (FC) type or nodular/bronchiectatic (NB) type by high-resolution CT. Additionally, chest radiological findings at the time of initial diagnosis were scored as follows. The lung fields were divided into six zones based on anatomical structures, i.e. right upper, right middle, right lower, left upper, left lingular, and left lower. When any abnormal findings including cavities, bronchiectasis, small nodules, consolidations, atelectasis, and so on were found in each zone at the time of diagnosis, they were each counted as one point and summed up in the six zones (maximum 6 points). The subjects were further classified based on their clinical course during the follow-up period into three categories: exacerbation, no change, or improvement. Each category was defined as follows: exacerbation, abnormal shadows increased; no change, abnormal shadows remained stable on the whole; and improvement, abnormal shadows decreased. The three categories were classified by five respiratory specialists in a blinded fashion.

\section{Patient management}

When patients did not receive medications for MAC during the observation period, radiographic findings were evaluated at the time of the diagnosis and 1 year later. When patients received medications for MAC during the observation period, they all began standardized combination antibiotic therapy, which consisted of oral clarithromycin, rifampicin, and ethambutol. ${ }^{7}$ Radiographic findings were evaluated at the start of medications and 1 year later. Those who discontinued medications and received medications for less than 6 months were excluded in the analysis of the clinical response to medications.

\section{Statistical analysis}

The patients' characteristics are presented as means \pm standard deviation (SD). Numerical data are expressed as numbers (\%). The differences between groups were examined for significance using the Mann-Whitney $U$ test or Fisher's exact test, as appropriate. To determine factors related to pulmonary MAC disease in treatment-naïve patients, univariable and 
multivariable Cox proportional hazard regression analyses were performed. All analyses were performed using SPSS Statistical software (version 22.0; IBM Japan, Tokyo, Japan). $P$ values $<0.05$ were considered significant.

\section{Results}

\section{Baseline characteristics of pulmonary MAC patients}

During the study period, 128 patients with pulmonary MAC disease were enrolled, and their baseline characteristics are summarized in Table 1. The causative organisms included M. avium in 100 patients (82.6\%) and M. intracellulare in 21 patients (17.4\%). Mixed infections ( $M$. avium and $M$. intracellulare) were found in 7 patients. All patients were HIV-negative. Their average age was $75.1 \pm 12.8$ years, and $80 \%$ of patients were over 65 years of age. Female (69.5\%), never-smoker (61.7\%), and NB type (78.9\%) were predominant in MAC patients. The average BMI was slightly low $\left(19.1 \mathrm{~kg} / \mathrm{m}^{2}\right)$. Medications for MAC were given to 39 (30.5\%) patients during the observation period. The average number of abnormal lung zones was 3.27.

\section{Comparison of pulmonary MAC patients' characteristics by smoking status}

A total of 124 subjects, excluding 4 patients with unknown smoking histories, were enrolled to compare the characteristics by smoking status (Table 2). There were no significant differences in age and laboratory data irrespective of smoking status. Compared with current and past smokers, never-smokers had a significantly higher ratio of females, lower BMI, fewer lung diseases other than MAC disease (including chronic lung disease such as chronic obstructive lung disease, bronchial asthma, lung cancer, and so on), and more extensive radiological findings.

\section{Comparison of pulmonary MAC patients' characteristics by sex}

Compared to male patients, female patients had significantly lower BMI, serum CRP levels, and lung diseases other than mycobacterial diseases, and significantly fewer had a smoking history, while they had significantly higher serum albumin levels (Table 3). Clinical outcomes were comparable, but female patients received MAC therapy significantly more frequently than male subjects.

\section{Comparison of female pulmonary MAC patients' characteristics by smoking status}

Approximately two-thirds of male subjects had a smoking history, as shown in Table 3. The effects of smoking on the clinical characteristics of pulmonary MAC disease were evaluated only in female subjects $(n=86)$ (Table 4). Compared to current and past smoker female patients, never-smoker female patients had significantly higher total protein, fewer lung diseases other than MAC, more extensive radiological findings, and a higher frequency of exacerbations at 1 year after diagnosis.

\section{Predictors of exacerbation in treatment-naïve pulmonary MAC subjects}

To exclude the bias of treatment because the treatment period was not fixed, univariate analysis was performed using only the data of treatment-naïve subjects (Table 5). The results indicated that female, never-smoker, fewer lung diseases other than MAC, more extensive radiological findings, and $\geq 3$ lobes involved were significantly associated with exacerbations. Multivariate analysis was performed with items that showed significant differences on univariate analysis. On multivariate 
analysis, fewer lung diseases other than MAC, more extensive radiological findings, and $\geq 3$ lobes involved were significantly associated with exacerbations, whereas female sex and never-smoker were not found to be exacerbating factors.

\section{Discussion}

In the present study, M. avium was the predominant species, found in $82.6 \%$ of MAC patients. The rate of patients with $M$. avium infection was similar to other recent reports. ${ }^{18}$ Similarly, there were more female than male patients in the present study. Generally, pulmonary MAC diseases develop more frequently in female than in male patients. A recent biological study reported the role of estrogen in the development of pulmonary MAC disease, whereas the role of sex in disease susceptibility is yet to be determined. ${ }^{19}$

Smoking status might also be associated with the development of pulmonary MAC disease. ${ }^{20}$ Smoking is a representative risk factor for human diseases, not only respiratory diseases, but also in general. Few diseases likely occur in never-smokers. For example, quitting smoking is a risk factor for hypersensitivity pneumonia ${ }^{21-23}$ and sarcoidosis. ${ }^{24}$ To determine the role of smoking status in the pathogenesis of pulmonary MAC disease, the present study compared patients' characteristics based on smoking status and found that never-smoker MAC patients had a significantly higher frequency of radiological exacerbations than current and past smokers. Nonetheless, it is impossible to conclude that never-smoking is a factor associated with exacerbations of pulmonary MAC disease, since many never-smoker MAC patients were female in the present study, and treatment status varied. Additionally, current and past smokers seemed to undergo radiological examinations more frequently than never-smokers, because they had a significantly higher frequency of other underlying lung diseases. Thus, there may be more opportunities to identify the early phase of pulmonary MAC disease in current and past smokers than in never-smokers.

To evaluate female sex as an exacerbating risk for pulmonary MAC disease, patients' characteristics were compared by sex. In treatment-naïve subjects, the frequency of radiological exacerbations was similar in both sexes. Although there was a significant difference in the frequency of MAC therapy between male and female patients, the responses to MAC therapy could not simply be compared by sex, though they seemed to be worse in women (7/7 of male and 16/32 of female patients improved following MAC therapy). The exact mechanisms of treatment resistance (cases that did not have improved radiological findings after 1 year despite MAC treatment for more than half a year) in female MAC patients remain unclear. In the present study, female patients had very low BMls, and the role of poor nutritional status was suggested, whereas serum albumin levels were rather higher in female patients, so that nutritional status alone did not explain the mechanisms. Other factors including adiponectin and wet environmental exposure might be involved in treatment resistance. ${ }^{12,17}$

In order to focus on smoking status and exclude sex as an exacerbating factor for MAC disease, patients' characteristics by smoking status were compared only in female patients. Never-smoker female patients had a significantly higher frequency of radiological exacerbations than current- and past-smoker female patients. This is probably due to significantly more radiological abnormalities at initial diagnosis in the never-smoker patients. Since never-smoker female patients had fewer other pulmonary diseases, diagnosis at the hospital was delayed, and as a result, they were likely discovered in an advanced state.

To determine the predictors of natural exacerbations, univariate logistic regression analysis was performed with the data of treatment-naïve patients, and it indicated that female sex, never-smoker, extensive abnormal shadows, $\geq 3$ lobes with abnormal shadows, and the absence of other underlying lung diseases were significant. Multivariate logistic regression analysis demonstrated that the presence of more extensive radiological findings in untreated patients (a larger affected area) was associated with exacerbations based on the probabilities of reactivation or dissemination of the infection. Female sex and never-smoker were not associated with exacerbations, and the associations of sex and smoking status with the clinical outcomes of pulmonary MAC disease could not be clarified. Although some authors reported radiological scoring methods in

pulmonary MAC disease, ${ }^{25,26}$ they were complicated and required much effort. Compared to these reports, the present scoring system had several limitations. It just counted the number of abnormal lesions irrespective of their volume and 
characteristics. Nonetheless, it can be easily performed in actual clinical practice and can potentially predict the natural course of pulmonary MAC disease, as suggested by this report.

\section{Conclusion}

Women and never-smokers were predominant among patients with pulmonary MAC diseases. The most critical exacerbating factor of pulmonary MAC disease over 1 year is the presence of extensive abnormal shadows, especially the presence of abnormal shadows in $\geq 3$ lobes in the lung. Thus, clinical attention should be focused on early diagnosis, since the presence of more extensive radiological findings in untreated patients (a larger affected area) was associated with exacerbations.

\section{Abbreviations}

ALB: serum albumin; CRP: serum C-reactive protein; CT: computed tomography; FC: fibrocavitary; MAC: Mycobacterium avium complex; NB: nodular/bronchiectatic; NTM: nontuberculous mycobacterium; TP: serum total protein

\section{Declarations}

\section{Acknowledgements}

None.

\section{Funding}

There was no specific funding for this research project.

\section{Availability of data and materials}

The anonymised datasets analysed during the current study are available from the corresponding author on reasonable request.

\section{Authors' contributions}

N. K. collected data, analysed data, created the tables and figures, designed the study, and wrote and revised the manuscript. C. N., T. O., K. W., K. N., C. I. , and H. M. collected data. H. M. critically revised the manuscript. All authors read and approved the final manuscript.

None of the authors received any funding from the public, commercial, or not-for-profit sectors.

\section{Competing interests}

All authors declare no conflicts of interest in relation to this article.

\section{Consent for publication}

Not required.

\section{Ethics approval and consent to participate}

This research was conducted using information previously collected in the course of normal care (without an intention to use it for research at the time of collection).

This study received ethical approval from the Special Committee of Toho University Ohashi Medical Center (project registration number $\mathrm{H} 16053)$. 


\section{References}

1. Marras TK, Chedore P, Ying AM, Jamieson F. Isolation prevalence of pulmonary non-tuberculous mycobacteria in Ontario, 1997-2003. Thorax 2007; 62: 661-6.

2. van Ingen J, Bendien SA, de Lange WC, Hoefsloot W, Dekhuijzen PN, Boeree MJ, et al. Clinical relevance of nontuberculous mycobacteria isolated in the Nijmegen-Arnhem region, The Netherlands. Thorax 2009; 64: 502-6.

3. Thomson RM. NTM working group at Queensland TB Control Centre and Queensland Mycobacterial Reference Laboratory Changing epidemiology of pulmonary nontuberculous mycobacteria infections. Infect. Dis. 2010; 16: 157683.

4. Prevots DR, Shaw PA, Strickland D, Jackson LA, Raebel MA, Blosky MA, et al. Nontuberculous mycobacterial lung disease prevalence at four integrated health care delivery systems. J. Respir. Crit. Care Med. 2010; 182: 970-6.

5. Winthrop KL, McNelley E, Kendall B , Marshall-Olson A, Morris C, Cassidy M, et al. Pulmonary nontuberculous mycobacterial disease prevalence and clinical features: an emerging public health disease. J. Respir. Crit. Care Med. 2010; 182: 977-82.

6. Simons S, van Ingen J, Hsueh PR, Van Hung N, Dekhuijzen PN, Boeree MJ, et al. Nontuberculous mycobacteria in respiratory tract infections, eastern Asia. Infect. Dis. 2011; 17: 343-9.

7. Griffith DE, Aksamit T, Brown-Elliott BA, Catanzaro A, Daley C, Gordin F, et al. An official ATS/IDSA statement: diagnosis, treatment, and prevention of nontuberculous mycobacterial diseases. J. Respir. Crit. Care Med. 2007; 175: 367-416.

8. Prince DS, Peterson DD, Steiner RM, Gottlieb JE, Scott R, Israel HL, et al. Infection with Mycobacterium avium complex in patients without predisposing conditions. Engl. J. Med. 1989; 321: 863-8.

9. Middleton AM, Chadwick MV, Nicholson AG, Dewar A, Groger RK, Brown EJ, et al. The role of Mycobacterium avium complex fibronectin attachment protein in adherence to the human respiratory mucosa. Microbiol. 2000; 38: $381-91$.

10. Michelini-Norris MB, Blanchard DK, Pearson CA, Djeu JY. Differential release of interleukin (IL)-1 alpha, IL-1 beta, and IL-6 from normal human monocytes stimulated with a virulent and an avirulent isogenic variant of Mycobacterium aviumintracellulare complex. Infect. Dis. 1992; 165: 702-9.

11. Yamazaki Y, Danelishvili L, Wu M, Hidaka E, Katsuyama T, Stang B, et al. The ability to form biofilm influences Mycobacterium avium invasion and translocation of bronchial epithelial cells. Microbiol. 2006; 8: 806-14.

12. Nishiuchi Y, Maekura R, Kitada S, Tamaru A, Taguri T, Kira Y, et al. The recovery of Mycobacterium avium-intracellulare complex (MAC) from the residential bathrooms of patients with pulmonary MAC. Infect. Dis. 2007; 45: 347-51.

13. Daley CL, Griffith DE. Pulmonary non-tuberculous mycobacterial infections. J. Tuberc. Lung Dis.2010; 14: 665-71.

14. Koh WJ, Jeong BH, Jeon K, Lee NY, Lee KS, Woo SY, et al. Clinical significance of the differentiation between Mycobacterium avium and Mycobacterium intracellulare in M avium complex lung disease. Chest 2012; 142: 1482-8.

15. Boyle DP, Zembower TR, Reddy S, Qi C. Comparison of clinical features, virulence, and relapse among Mycobacterium avium complex species. J. Respir. Crit. Care Med. 2015; 191: 1310-7.

16. Ito Y, Hirai T, Fujita K, Maekawa K, Niimi A, Ichiyama S, et al. Increasing patients with pulmonary Mycobacterium avium complex disease and associated underlying diseases in Japan. Infect. Chemother. 2015; 21: 352-6.

17. Kim RD, Greenberg DE, Ehrmantraut ME, Guide SV, Ding L, Shea Y, et al. Pulmonary nontuberculous mycobacterial disease: prospective study of a distinct preexisting syndrome. J. Respir. Crit. Care Med.2008; 178: 1066-74.

18. Morimoto K, Hasegawa N, Izumi K, Namkoong H, Uchimura K, Yoshiyama T, et al. A laboratory-based analysis of nontuberculous mycobacterial lung disease in Japan from 2012 to 2013. Am. Thorac. Soc. 2017; 14: 49-56.

19. Tsuyuguchi K, Suzuki K, Matsumoto H, Tanaka E, Amitani R, Kuze F. Effect of estrogen on Mycobacterium avium complex pulmonary infection in mice. Exp. Immunol. 2001; 123: 428-34.

20. Kotilainen H, Valtonen V, Tukiainen P, Poussa T, Eskola J, Järvinen A. Clinical symptoms and survival in non-smoking and smoking HIV-negative patients with non-tuberculous mycobacterial isolation. J. Infect. Dis. 2011; 43: 188-96. 
21. Morgan DC, Smyth JT, Lister RW, Pethybridge RJ. Chest symptoms and farmer's lung: a community survey. J. Ind. Med. 1973; 30: 259-65.

22. Arima K, Ando M, Ito K, Sakata T, Yamaguchi T, Araki S, et al. Effect of cigarette smoking on prevalence of summer-type hypersensitivity pneumonitis caused by Trichosporon cutaneum. Environ. Health 1992; 47: 274-8.

23. Warren CP. Extrinsic allergic alveolitis: a disease commoner in non-smokers. Thorax 1977; 32: 567-9.

24. Holt PG. Immune and inflammatory function in cigarette smokers. Thorax 1987; 42: 241-9.

25. Song JW, Koh WJ, Lee KS, Lee JY, Chung MJ, Kim TS, et al. High-resolution CT findings of Mycobacterium aviumintracellulare complex pulmonary disease: correlation with pulmonary function test results. Am. J. Roentgenol. 2008; 191: 160-6.

26. Kurashima A, Morimoto K, Horibe M, Hoshino Y, Shiraishi Y, Kudow S. A method for visual scoring of pulmonary Mycobacterium Avium Complex Disease: “NICE Scoring System”. Mycobac. 2013; 3: 127.

\section{Tables}

Table 1. Baseline characteristics of pulmonary MAC patients $(n=128)$

\begin{tabular}{|c|c|}
\hline Age, $y$ & $75.1 \pm 12.8$ \\
\hline Sex (male/female) & $39(30.5 \%) / 89(69.5 \%)$ \\
\hline Smoking history (current/past/never/unknown) & $1(1 \%) / 44(34.4 \%) / 79(61.7 \%) / 4(3.1 \%)$ \\
\hline BMI $\left(\mathrm{kg} / \mathrm{m}^{2}\right)$ & $19.05 \pm 2.96$ \\
\hline $\mathrm{TP}(\mathrm{g} / \mathrm{dl})$ & $7.29 \pm 0.77$ \\
\hline $\operatorname{ALB}(\mathrm{g} / \mathrm{dl})$ & $3.70 \pm 0.61$ \\
\hline $\mathrm{CRP}(\mathrm{mg} / \mathrm{dl})$ & $1.53 \pm 3.29$ \\
\hline Previous tuberculosis, n (\%) & $13(10.2 \%)$ \\
\hline Lung disease other than mycobacterial disease, $\mathrm{n}(\%)$ & $52(40.6 \%)$ \\
\hline Smear/culture/BAL & $29(22.7 \%) / 64(50 \%) / 35(27.3 \%)$ \\
\hline Positive AFB smear, n (\%) & $29(22.7 \%)$ \\
\hline M. avium/M. intracellulare/avium+intracellulare & $100(78.1 \%) / 21(16.4 \%) / 7(5.5 \%)$ \\
\hline FC type/NB type & $27(21.1 \%) / 101(78.9 \%)$ \\
\hline MAC therapy during follow-up & $39(30.5 \%)$ \\
\hline Zone of radiological findings (n.) & $3.27 \pm 1.54$ \\
\hline
\end{tabular}

Data are presented as means \pm SD (standard deviation) or numbers (\%).

$\mathrm{AFB}=$ acid-fast bacilli, $\mathrm{ALB}=$ serum albumin, $\mathrm{CRP}=$ serum $\mathrm{C}$-reactive protein, $\mathrm{FC}=$ fibrocavitary, $\mathrm{MAC}=$ Mycobacterium avium complex, $\mathrm{NB}=$ nodular $/$ bronchiectatic, $\mathrm{TP}=$ serum total protein 
Table 2. Comparison of pulmonary MAC patients' characteristics by smoking status $(\mathrm{n}=124)$

\begin{tabular}{|c|c|c|c|}
\hline & Current and past smokers $(n=45)$ & Never-smokers $(n=79)$ & $P$-value \\
\hline Age, y & $75.0 \pm 13.9$ & $75.6 \pm 12.0$ & 0.76 \\
\hline Sex (male/female) & 28 / 17 (62.2\% / 37.8\%) & 10 / 69 (12.7\% / 87.3\%) & $<0.001 * *$ \\
\hline BMI $\left(\mathrm{kg} / \mathrm{m}^{2}\right)$ & $19.8 \pm 3.28$ & $18.4 \pm 2.63$ & $0.03^{*}$ \\
\hline $\mathrm{TP}(\mathrm{g} / \mathrm{dl})$ & $7.15 \pm 0.88$ & $7.36 \pm 0.71$ & 0.29 \\
\hline $\mathrm{ALB}(\mathrm{g} / \mathrm{dl})$ & $3.56 \pm 0.70$ & $3.77 \pm 0.56$ & 0.13 \\
\hline $\mathrm{CRP}(\mathrm{mg} / \mathrm{dl})$ & $2.10 \pm 4.42$ & $1.25 \pm 2.51$ & 0.16 \\
\hline Previous tuberculosis, n (\%) & $5(11.1 \%)$ & $8(10.1 \%)$ & 0.56 \\
\hline Lung disease other than & $28(62.2 \%)$ & $26(32.9 \%)$ & $0.001 * *$ \\
\hline \multicolumn{4}{|l|}{ mycobacterial disease, n (\%) } \\
\hline Positive MAC smear, n (\%) & $9(17.8 \%)$ & $20(25.3 \%)$ & 0.23 \\
\hline M. avium/M. & 36 (80\%) / 7 (15.6\%) / 2 (4.4\%) & $62(78.4 \%) / 13(16.5 \%) / 4(5.0 \%)$ & 0.51 \\
\hline \multicolumn{4}{|l|}{ intracellulare/avium+intracellulare } \\
\hline FC type/NB type & $10(22.2 \%) / 35$ (77.8\%) & 17 (21.5\%) / 62 (78.5\%) & 0.93 \\
\hline Zone of radiological findings, n (\%) & $2.76 \pm 1.45$ & $3.58 \pm 1.52$ & $0.003^{* *}$ \\
\hline Improvement/no & $10(22.2 \%) / 28(62.2 \%) / 6(13.3 \%) / 1(2.2 \%)$ & $13(16.5 \%) / 41(51.9 \%) / 21(26.6 \%) / 4(5 \%)$ & 0.09 \\
\hline \multicolumn{4}{|l|}{ change/exacerbation/unknown } \\
\hline MAC therapy ${ }^{\ddagger}$ & $13(28.9 \%)$ & $26(32.9 \%)$ & 0.40 \\
\hline
\end{tabular}

‡: consisted of oral clarithromycin, rifampicin, and ethambutol over 6 months (MAC therapy). See footnote of Table 1 for expansions of abbreviations.

*: $P<0.05 ; * *: P<0.01$

Table 3. Comparison of pulmonary MAC patients' characteristics by sex $(n=128)$ 


\begin{tabular}{|c|c|c|c|}
\hline & Male $(n=39)$ & Female $(n=89)$ & $\begin{array}{l}P \text { - } \\
\text { value }\end{array}$ \\
\hline Age, y & $78.5 \pm 9.15$ & $73.7 \pm 13.9$ & 0.05 \\
\hline $\begin{array}{l}\text { Smoking history } \\
\text { (current/past/never/unknown) }\end{array}$ & 0 / 28 (73.1\%) / 10 (26.3\%) / 1 & $1 / 16$ (19.8\%) / 69 (80.2\%) / 3 & $<0.01^{*}$ \\
\hline BMI $\left(\mathrm{kg} / \mathrm{m}^{2}\right)$ & $20.3 \pm 2.84$ & $18.5 \pm 2.84$ & $<0.01 *$ \\
\hline $\mathrm{TP}(\mathrm{g} / \mathrm{dl})$ & $7.16 \pm 0.97$ & $7.36 \pm 0.67$ & 0.55 \\
\hline $\operatorname{ALB}(g / d l)$ & $3.48 \pm 0.74$ & $3.79 \pm 0.53$ & $0.01 *$ \\
\hline $\mathrm{CRP}(\mathrm{mg} / \mathrm{dl})$ & $2.17 \pm 3.38$ & $1.26 \pm 3.23$ & $0.01 *$ \\
\hline Previous tuberculosis, n (\%) & $4(10.3 \%)$ & $9(10.1 \%)$ & 0.60 \\
\hline $\begin{array}{l}\text { Lung disease other than mycobacterial } \\
\text { disease, } \mathrm{n}(\%)\end{array}$ & $24(61.5 \%)$ & $38(42.7 \%)$ & $0.04 *$ \\
\hline Positive MAC smear, n (\%) & $9(23.1 \%)$ & $20(22.5 \%)$ & 0.55 \\
\hline $\begin{array}{l}\text { M. avium/M. } \\
\text { intracellulare/avium+intracellulare }\end{array}$ & $33(84.6 \%) / 5(12.8 \%) / 1$ (2.6\%) & 67 (73.5\%) / 16 (18.0\%) / 6 (6.7\%) & 0.29 \\
\hline FC type/NB type & 8 (20.5\%) / 31 (79.5\%) & 19 (21.3\%) / 70 (78.7\%) & 0.56 \\
\hline Zone of radiological findings (n) & $3.08 \pm 1.58$ & $3.36 \pm 1.52$ & 0.46 \\
\hline $\begin{array}{l}\text { Improvement/no } \\
\text { change/exacerbation/unknown }\end{array}$ & $8(20.5 \%) / 23(59 \%) / 6(15.4 \%) / 2(5.1 \%)$ & $16(18 \%) / 47(52.8 \%) / 21(23.6 \%) / 5(5.6 \%)$ & 0.23 \\
\hline MAC therapy ${ }^{\ddagger}$ & 7 (17.9\%) & $32(36.0 \%)$ & $0.03^{*}$ \\
\hline
\end{tabular}

See footnotes of Tables 1 and 2 for expansions of abbreviations.

Table 4. Comparison of pulmonary MAC female patients' characteristics by smoking status ( $\mathrm{n}=86$ ) 


\begin{tabular}{|c|c|c|c|}
\hline & $\begin{array}{l}\text { Current and past smokers } \\
(\mathrm{n}=17)\end{array}$ & Never-smokers $(n=69)$ & $P$-value \\
\hline Age, $y$ & $68.7 \pm 18.3$ & $75.3 \pm 12.2$ & 0.21 \\
\hline BMI $\left(\mathrm{kg} / \mathrm{m}^{2}\right)$ & $18.7 \pm 3.75$ & $18.3 \pm 2.64$ & 0.84 \\
\hline $\mathrm{TP}(\mathrm{g} / \mathrm{dl})$ & $7.01 \pm 0.57$ & $7.42 \pm 0.68$ & $0.02 *$ \\
\hline $\operatorname{ALB}(g / d l)$ & $3.80 \pm 0.60$ & $3.80 \pm 0.53$ & 0.85 \\
\hline $\mathrm{CRP}(\mathrm{mg} / \mathrm{dl})$ & $1.58 \pm 5.31$ & $1.22 \pm 2.60$ & 0.51 \\
\hline Previous tuberculosis, n (\%) & $2(11.8 \%)$ & $7(10.1 \%)$ & 0.56 \\
\hline $\begin{array}{l}\text { Lung disease other than mycobacterial } \\
\text { disease, } \mathrm{n}(\%)\end{array}$ & $12(70.6 \%)$ & $26(37.7 \%)$ & $0.01 *$ \\
\hline Positive MAC smear, n (\%) & $3(17.6 \%)$ & $17(24.6 \%)$ & 0.40 \\
\hline $\begin{array}{l}\text { M. avium/M. } \\
\text { intracellulare/avium+intracellulare }\end{array}$ & $\begin{array}{l}14(82.6 \%) / 2(11.8 \%) / 1 \\
(5.9 \%)\end{array}$ & $51(73.9 \%) / 13$ (18.8\%) / 3 (4.3\%) & 0.43 \\
\hline FC type/NB type & $4(23.5 \%) / 13(76.5 \%)$ & $14(20.3 \%) / 55$ (79.7\%) & 0.49 \\
\hline Zone of radiological findings, $\mathrm{n}(\%)$ & $2.41 \pm 1.28$ & $3.54 \pm 1.48$ & $0.006^{* *}$ \\
\hline $\begin{array}{l}\text { Improvement/no } \\
\text { change/exacerbation/unknown }\end{array}$ & $6(35.3 \%) / 10(58.8 \%) / 1(5.9 \%) / 0$ & $10(14.5 \%) / 36(52.2 \%) / 18(26.1 \%) / 5(7.2 \%)$ & $0.04 *$ \\
\hline MAC therapy ${ }^{\ddagger}$ & $8(47.1 \%)$ & $20(29.0 \%)$ & 0.13 \\
\hline
\end{tabular}

See footnotes of Tables 1 and 2 for expansions of abbreviations.

Table 5. Predictors of exacerbation in treatment-naïve pulmonary MAC subjects $(n=80)$

\begin{tabular}{|c|c|c|c|c|}
\hline & \multicolumn{2}{|l|}{ Univariate analysis } & \multicolumn{2}{|l|}{ Multivariate analysis } \\
\hline & HR $(95 \% \mathrm{CI})$ & $P$-value & HR $(95 \% \mathrm{CI})$ & $P$-value \\
\hline Age, $y$ & $0.963(0.922-1.005)$ & 0.085 & & \\
\hline Sex (Female) & $3.116(1.022-9.498)$ & $0.046^{*}$ & & \\
\hline Never-smoker & $3.900(1.283-11.85)$ & $0.016^{*}$ & & \\
\hline $\operatorname{BMI}\left(\mathrm{kg} / \mathrm{m}^{2}\right)$ & $0.990(0.839-1.168)$ & 0.904 & & \\
\hline $\mathrm{TP}(\mathrm{g} / \mathrm{dl})$ & $1.702(0.922-3.140)$ & 0.089 & & \\
\hline $\operatorname{ALB}(g / d l)$ & $1.920(0.863-4.274)$ & 0.110 & & \\
\hline $\mathrm{CRP}(\mathrm{mg} / \mathrm{dl})$ & $0.944(0.797-1.118)$ & 0.503 & & \\
\hline Previous tuberculosis, n (\%) & $1.905(0.523-6.939)$ & 0.329 & & \\
\hline Lung disease other than mycobacterial disease, $\mathrm{n}(\%)$ & $0.287(0.108-0.767)$ & $0.013^{*}$ & $0.306(0.109-0.856)$ & $0.024^{*}$ \\
\hline Positive MAC smear, n (\%) & $2.222(0.741-6.663)$ & 0.154 & & \\
\hline M. intracellulare & $0.889(0.240-3.297)$ & 0.860 & & \\
\hline FC type & $1.190(0.355-3.991)$ & 0.085 & & \\
\hline Zone of radiological findings, $\mathrm{n}(\%)$ & $1.587(1.133-2.222)$ & $0.007^{* *}$ & $1.565(1.103-2.221)$ & $0.012^{*}$ \\
\hline Involved lobes $\geq 3$ & $4.523(1.488-13.75)$ & $0.008^{* *}$ & $4.349(1.385-13.65)$ & $0.012^{*}$ \\
\hline Involved lobes $\geq 2$ & $4.252(0.962-18.79)$ & 0.056 & & \\
\hline
\end{tabular}


Figures

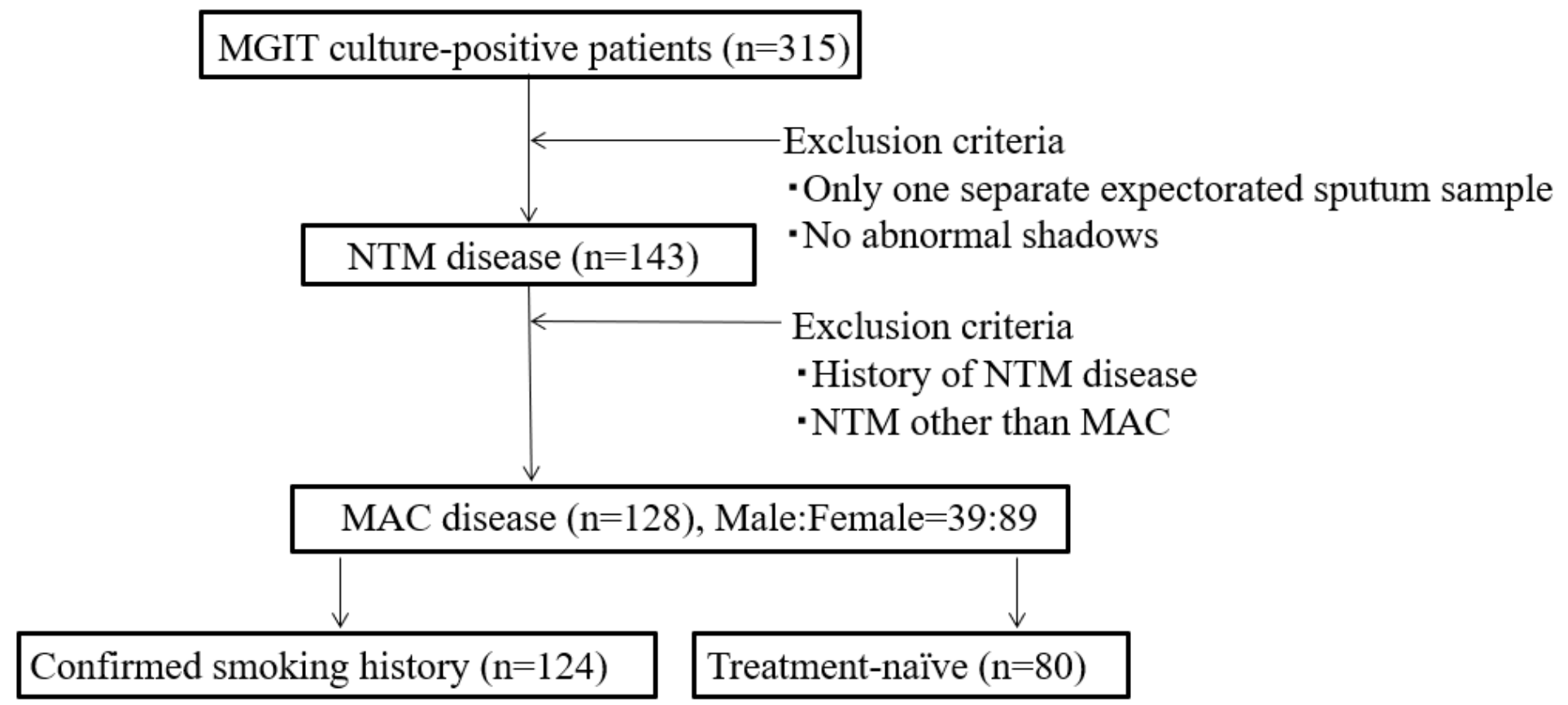

\section{Figure 1}

Flow chart of patients diagnosed with pulmonary MAC disease between April 2011 and May 2016. MGIT=mycobacterial growth indicator tube NTM=nontuberculous mycobacterium MAC=Mycobacterium avium complex 